\title{
Micro-arc Oxidation Coating Formed on Anodized Aluminum Surface under Different Pulse Frequencies
}

\author{
Xuping Zhao, Dan Liu, Jieqin Lu, Guoying Wei \\ College of Materials Science \& Engineering, China Jiliang University, Hang Zhou \\ *E-mail: guoyingwei@ sina.com
}

doi: $10.20964 / 2017.09 .02$

Received: 17 March 2017 / Accepted: 19 June 2017 / Published: 13 August 2017

\begin{abstract}
The microstructure and corrosion behavior of the micro-arc oxidation (MAO) coating formed on the surface of anodization film under different pulse frequencies have been investigated. Microstructure of the coatings were examined by scanning electron microscopy (SEM), energy-dispersive spectroscopy (EDS) and X-ray diffractometer (XRD). Corrosion resistance of anodized coatings were evaluated by potentiodynamic polarization. The results reveal that the coating surface is more compact and the corrosion resistance is better with corrosion current one order of magnitude lower than coatings at lower frequencies. The surface roughness and hardness increased with the pulse frequencies. Al peaks decreased with the pulse frequency, indicating that more and more compact structure existed in the coatings.
\end{abstract}

Keywords: aluminum; anodization; micro-arc oxidation; pulse frequency

\section{FULL TEXT}

(C) 2017 The Authors. Published by ESG (www.electrochemsci.org). This article is an open access article distributed under the terms and conditions of the Creative Commons Attribution license (http://creativecommons.org/licenses/by/4.0/). 